\title{
sciendo
}

\author{
Current Issues in Pharmacy and Medical Sciences
}

Formerly ANNALES UNIVERSITATIS MARIAE CURIE-SKIODOWSKA, SECTIO DDD, PHARMACIA

journal homepage: http://www.curipms.umlub.pl/

\section{Clinical and laboratory findings in elderly with Community- Acquired Pneumonia in Babol, northern Iran - 2017-2019}

\author{
Saleh Habibi ${ }^{1}$, Arefeh Babazadeh ${ }^{2}{ }^{-}$, Soheil Ebrahimpour ${ }^{2}$, \\ Parisa SabBagh ${ }^{2}$, Mehran ShOKRI ${ }^{2 *}$
}

${ }^{1}$ Student Research Committee, Babol University of Medical Sciences, Babol, Iran

${ }^{2}$ Infectious Diseases and Tropical Medicine Research Center, Health Research Institute, Babol University of Medical Sciences, Babol, Iran

\section{ARTICLE INFO}

Received 12 January 2021

Accepted 28 June 2021

\section{Keywords:}

community-acquired

pneumonia,

elderly,

clinical manifestation.

\begin{abstract}
Morbidity and mortality are higher in older adults with community-acquired pneumonia (CAP) than in other age groups. Also, CAP in older adults has various clinical manifestations with other. A higher mortality rate in the elderly with CAP may contribute to a delay in management. Consequently, the purpose of this study was to investigate the clinical and laboratory manifestations of CAP in the elderly. This cross-sectional study was conducted on 221 elderly patients with CAP who were admitted to Ayatollah Rouhani Hospital, in Babol, northern of Iran, in 2017-2019. Patient outcomes included 170 cases that recovered from CAP, and 51 cases that died of complications. Patients were evaluated in terms of their clinical and laboratory manifestations. The most common symptoms of pneumonia were cough $(79.6 \%)$, sputum $(73.8 \%)$, weakness $(72.9 \%)$, fever (56\%), dyspnea (46.2\%). The most frequent underlying disease was ischemic heart disease (43.9\%). In our study, clinical and laboratory characteristics in older patients with CAP were evaluated and compared with other studies confirming past findings, but there were differences in some cases, such as vital signs, gastrointestinal symptoms, and disturbance of the level of consciousness. Therefore, it recommends carefully taking the patients' initial histories and accurately recording their clinical and laboratory symptoms.
\end{abstract}

\section{INTRODUCTION}

Pneumonia has been defined as a lower respiratory tract infection involving the lung parenchyma [1]. Pneumonia is the most common cause of death-related illness and is a significant life threat to the elderly [2]. Communityacquired pneumonia (CAP) refers to pneumonia contracted by a person outside of the healthcare system [3]. CAP is a serious infection and is associated with high morbidity and mortality, particularly in the elderly. The annual incidence of the CAP ranges from 5.16 to 6.11 per 1.000 people. The CAP rate increases with increasing age [4].

CAP is an extremely widespread pathology, the etiology of which is assessed by the characteristics of the geographical area [5,6]. Streptococcus pneumoniae (S. pneumoniae) and Haemophilus influenza (H. influenzae) are still the most common pathogens in older people, although CAP may also be caused by some multidrug-resistant organisms (MDROs) [7,8]. CAP typically includes fever, cough, chest pain, shortness of breath, sputum production, headache,

\footnotetext{
* Corresponding author

e-mail: mshokri2015@yahoo.com
}

fatigue and dyspnea $[9,10]$. Moreover, leukocytosis is associated with pneumonia, and elderly people often present atypical symptoms and have no fever [11].

The elderly are more likely to develop severe pneumonia, and CAP remains the leading cause of death from infectious diseases - especially among the elderly. Given the increase in life expectancy and dramatic increase in the aging of the population, we will see a significant increase in the number of cases of pneumonia among the elderly, as well as deaths from pneumonia [12-15].

The purpose of the current study is to determine clinical and laboratory outcomes among the elderly with CAP in Babol, northern Iran, from 2017 to 2019.

\section{MATERIAL AND METHODS}

This cross-sectional study was carried out in 221 hospitalizations with CAP, who were admitted to the Ayatollah Rouhani hospital in Babol, northern Iran, between March 2017 and March 2019. The present study was approved by the ethics committee of Babol University of Medical 
Sciences (Code: MUBABOL.HRI.REC.1398.147). All the enrolled patients were notified of the study and provided informed written consent.

\section{Inclusion Criteria}

This criteria included: (a) age $>65$ years, (b) some clinical symptoms such as cough with or without expectoration, fever, dyspnea and pleuritic chest pain, as well as (c) clinical signs such as tachypnea, reduced chest movements, increased vocal fremitus, bronchial breath sounds, vocal resonance and crepitations. Further criteria involved: (d) Radiological evidence for pneumonia with no clinical evidence for pneumonia.

\section{Exclusion Criteria}

Such criteria comprised: (a) Nosocomial pneumonia within the previous two weeks, (b) Tuberculosis (TB), (c) Human immunodeficiency virus (HIV) - positive status, and (d) Lung cancers. Demographic information was recorded via checklist. This checklist, completed for each patient, included their clinical signs and symptoms (cough, sputum production, dyspnea, chest pain, fever, tachycardia and tachypnea), abnormal findings in pulmonary auscultation, and laboratory results (erythrocyte sedimentation rate (ESR), c-reactive protein (CRP) and white blood cells (WBCs)). For the purposes of the study, comorbid illnesses have been defined as the existence of co-existing ischemic heart disease, chronic obstructive pulmonary disease (COPD), cancers, neurological disease, diabetes, chronic kidney disease (CKD) and chronic liver disease.

\section{Statistical Analysis}

All statistical analyses were performed in SPSS version 16.0 (SPSS Inc., Chicago, IL, U.S.). The data are presented as mean and standard deviation (SD) and percentage. $\mathrm{P}$-value $<0.05$ were found to be statistically significant.

\section{RESULTS}

The present study was carried out at Ayatollah Rouhani Hospital between March 2017 and March 2019. This prospective study involved 221 cases (158 males, 63 females) of hospitalized CAP patients over 65 years old. Patients were aged from 66 to 94 years. The mean age was $81 \pm 6$ years. Among the clinical symptoms, cough was the most common (79.6\%), and oral infection was the least common (5\%) (Table 1). A total of 221 subjects had 9 underlying disease types (Table 2), the most common of which was ischemic heart disease (43.9\%). Underlying the importance of vital signs in the initial evaluation of the patient, 96 patients $(43.4 \%)$ had an axillary temperature between 36 and $37.5^{\circ} \mathrm{C}$, and $42(19 \%)$ patients had temperatures between 37.5 and $38^{\circ} \mathrm{C}$. Moreover, $83(37.6 \%)$ patients had axillary temperatures above $38^{\circ} \mathrm{C}$. Details of para clinical variables are shown in Table 3.
Table 1. The frequency of clinical symptoms in elderly patients

\begin{tabular}{|l|l||l|l|}
\hline \multicolumn{1}{|c|}{ Symptoms } & Frequency & \multicolumn{1}{|c|}{ Symptoms } & Frequency \\
\hline Cough & $176(79.6 \%)$ & Myalgia & $60(27.1 \%)$ \\
\hline Sputum & $163(73.8 \%)$ & $\begin{array}{l}\text { Loss of } \\
\text { Consciousness }\end{array}$ & $39(17.6 \%)$ \\
\hline Weakness & $161(72.9 \%)$ & $\begin{array}{l}\text { Nausea and } \\
\text { Vomiting }\end{array}$ & $24(10.9 \%)$ \\
\hline Fever & $125(56 \%)$ & leural pain & $14(6.3 \%)$ \\
\hline Dyspnea & $102(46.2 \%)$ & Oral infection & $11(5 \%)$ \\
\hline
\end{tabular}

Table 2. The frequency of underlying diseases in elderly patients

\begin{tabular}{|l|c||l|l|}
\hline \multicolumn{1}{|c|}{$\begin{array}{c}\text { Underlying } \\
\text { diseases }\end{array}$} & Frequency & \multicolumn{1}{|c|}{$\begin{array}{c}\text { Underlying } \\
\text { diseases }\end{array}$} & Frequency \\
\hline $\begin{array}{l}\text { Ischemic heart } \\
\text { disease }\end{array}$ & $97(43.9 \%)$ & Stroke & $46(20.8 \%)$ \\
\hline Hypertention & $90(40.7 \%)$ & Thyroid & $18(8.1 \%)$ \\
\hline Hyper lipidemia & $87(39.4 \%)$ & Malignancy & $14(6.3 \%)$ \\
\hline Lung diseases & $83(37.6 \%)$ & $\begin{array}{l}\text { Chronic kidney } \\
\text { diseases }\end{array}$ & $10(4.5 \%)$ \\
\hline Diabetes & $59(26.7 \%)$ & \multicolumn{3}{|l}{} \\
\hline
\end{tabular}

Table 3. The paraclinical status in elderly

\begin{tabular}{|c|c|c|}
\hline \multicolumn{2}{|c|}{ Paraclinical status } & \multirow{2}{*}{$\begin{array}{r}\text { Frequency } \\
56(25.6 \%)\end{array}$} \\
\hline ESR & $<30$ & \\
\hline & $30-60$ & 77 (36.5\%) \\
\hline & $60-100$ & $28(13.3 \%)$ \\
\hline & $>100$ & $50(23.7 \%)$ \\
\hline \multirow[t]{3}{*}{ CRP } & $<30$ & 83 (41.3\%) \\
\hline & $30-60$ & $53(26.4 \%)$ \\
\hline & $>60$ & $42(32.3 \%)$ \\
\hline \multirow[t]{3}{*}{ WBC } & $<4000$ & $11(5 \%)$ \\
\hline & $4000-12000$ & $138(62.4 \%)$ \\
\hline & $>12000$ & $72(32.6 \%)$ \\
\hline Hemoglobin & $<10000$ & $62(28.1 \%)$ \\
\hline Blood culture & & $34(15.4 \%)$ \\
\hline
\end{tabular}

WBC - White blood cell

In this study, the method of receiving antibiotics, the number, and type of antibiotics administered during hospitalization was analyzed. Herein, 147 (66.5\%) patients had received antibiotics in the past three months. Furthermore, outcomes in older patients with CAP were included. As a result, we found that 170 patients recovered from CAP, while 51 of the cases died from complications associated with pneumonia.

\section{DISCUSSION}

The CAP is a common cause of hospitalization and mortality among the world's elderly. With regard to the etiology of pneumonia, some studies have shown that the etiology of CAP in older adults does not differ from other age groups, however, cases in the elderly may look different than that of young people, especially in symptoms and outcomes. In the recent study, cough was the most common symptom among older adults, and this finding is consistent with other studies in India, Japan and Spain [16-18]. In contrast, the prevalence of impaired consciousness, nausea and vomiting was higher than in other studies $[17,18]$. Regarding vital signs, the percentage of patients with more than 30 breaths 
per minute was $17 \%$, and was less when compared to the outcome of the work of Mortensen et al. and Hasibi et al. (49\% and $19.3 \%$, respectively) $[19,20]$. What is more, the frequency for patients with a heart rate greater than 90 beats per minute was 25.4, which is also less than that found in some other studies [19]. This can be related to measurement and recording accuracy, as well as differences in the measurement tool.

It is recognized that several risk factors, such as underlying medical conditions, predisposes the elderly to pneumonia, and are also related to the CAP's incidence and outcome [21]. In the present study, the most common diseases were ischemic heart disease and hypertension (43.9\% and 40.7\%, respectively). In Jafari's study, the most common underlying diseases were heart and neurological diseases [18,22]. Diverse studies have reported different statistics on the prevalence of underlying diseases in the elderly due to different conditions in lifestyles, epidemiological and geographical regions.

During our study, $57 \%$ of all patients were treated with two antibiotics. Overall, $85 \%$ patients received two or three antibiotics. The most common antibiotics in our study were third-generation cephalosporins such as ceftriaxone and macrolides (azithromycin), with a frequency of $81.9 \%$ and $55.7 \%$, respectively. Kobashi et al. indicated that the most common antibiotic was levofloxacin, the frequency of dosage, along with that indicated in the Berger et al. study are similar to our study $[17,23]$. We saw that the mortality rate was $23 \%$, with $77 \%$ of all patients recovering completely. This outcome is consistent with several studies.

Despite all available treatment options, pneumonia remains the leading cause of death among the elderly. The mortality rates range from $4.9 \%$ to $48 \%$ depending on the research. For instance, in the study of Kaplan et al., this figure was $11 \%$, and in the study by Abdullah et al., $84 \%$ of patients recovered, while $16 \%$ died $[16,24]$. Differences in mortality may be affected by underlying diseases, the mean age of patients admitted to the study, the state of the support system, and the nutritional status of patients [24].

\section{CONCLUSION}

In the present study, clinical and laboratory findings in elderly patients with CAP were consistent with other studies. Therefore, it is recommended to pay attention to initial patient history, clinical and laboratory data in the diagnosis, and begin treatment as early as possible. Due to the differences in the clinical manifestations of pneumonia in the elderly, knowing more about these signs and symptoms will help in obtaining timely care.

\section{ACKNOWLEDGEMENT}

All authors thank the department of infectious diseases of Babol University of Medical sciences, Iran for their help. The project was funded by Babol University of Medical Sciences (Grant number: 9807927).

\section{CONFLICTS OF INTERESTS}

There are no conflicts of interest

\section{ORCID iDs}

Arefeh Babazadeh (1)https://orcid.org/0000-0002-1362-7203

\section{REFERNCES}

1. Mandell LA. Community-acquired Pneumonia: An overview. Postgrad Med. 2015;127(6):607-15.

2. Shokri M, Ghasemian R, Bayani M, Maleh PA, Kamrani M, SadeghiHaddad-Zavareh M, et al. Serum and alveolar procalcitonin had a weak diagnostic value for ventilator-associated pneumonia in patients with pulmonary infection score $\geq 6$. Rom J Intern Med. 2018;56(1):9-14.

3. Kalil AC, Metersky ML, Klompas M, Muscedere J, Sweeney DA, Palmer LB, et al. Management of adults with hospital-acquired and ventilator-associated Pneumonia: 2016 clinical practice guidelines by the Infectious Diseases Society of America and the American Thoracic Society. Clin Infecti Dis. 2016;63(5):e61-e111.

4. Marrie TJ, Huang JQ. Epidemiology of community-acquired Pneumonia in Edmonton, Alberta: an emergency department-based study. Can Respir J. 2005;12(3):139-42.

5. Marrie TJ, Haldane EV, Faulkner RS, Durant H, Kwan C. Communityacquired pneumonia requiring hospitalization: is it different in the elderly? J Am Geriatr Soc. 1985;33(10):671-80.

6. Fernández-Sabé N, Carratalà J, Rosón B, Dorca J, Verdaguer R, Manresa $\mathrm{F}$, et al. Community-acquired pneumonia in very elderly patients: causative organisms, clinical characteristics, and outcomes. Medicine. 2003;82(3):159-69.

7. Gadsby NJ, Russell CD, McHugh MP, Mark H, Conway MA, Laurenson IF, et al. Comprehensive molecular testing for respiratory pathogens in community-acquired pneumonia. Clin Infect Dis. 2016;62(7):817-23.

8. Jain S, Self WH, Wunderink RG, Fakhran S, Balk R, Bramley AM, et al. Community-acquired Pneumonia requiring hospitalization among US adults. N Engl J Med. 2015;373(5):415-27.

9. Marrie TJ. Community-acquired Pneumonia. Clin Infecti Dis. 1994;18(4):501-13.

10. Metlay JP, Kapoor WN, Fine MJ. Does this patient have communityacquired pneumonia?: Diagnosing pneumonia by history and physical examination. JAMA. 1997;278(17):1440-5.

11. Vukkadala N, Auerbach A. Clinical utility of routine CBC testing in patients with community-acquired pneumonia. J Hosp Med. 2017;12(5):336-8.

12. Anevlavis S, Bouros D. Scoring systems in community acquired pneumonia. Pneumon. 2009;22(4):286-9.

13. España PP, Capelastegui A, Gorordo I, Esteban C, Oribe M, Ortega $\mathrm{M}$, et al. Development and validation of a clinical prediction rule for severe community-acquired pneumonia. Am J Respir Crit Care Med. 2006;174(11):1249-56.

14. Cheraghi M, Tavakol H, Tabatabaei S, Hashemi B. Clinical manifestation of patients with Acquired Pneumonia admitted in the respiratory ward of Imam Khomeini Hospital in Ahvaz. J Prev Med. 2014;1(1):51-7.

15. Momen-Heravi M, Razzaghi R, Mousavi G, Zamani-Fard S. Factors affecting the outcome of community-acquired pneumonia among the patients hospitalized in Beheshti hospital (Kashan-Iran). Feyz J Kashan Univers Med Sci. 2017;21(2):197-205.

16. Abdullah BB, Zoheb M, Ashraf SM, Ali S, Nausheen N. A study of community-acquired pneumonias in elderly individuals in Bijapur, India. ISRN Pulmonol. 2012;2012:1-10.

17. Kobashi Y, Okimoto N, Matsushima T, Soejima R. Clinical analysis of community-acquired pneumonia in the elderly. Intern Med. 2001;40(8):703-7.

18. Torres A, Dorca J, Zalacain R, Bello S, El-Ebiary M, Molinos L, et al. Community-acquired pneumonia in chronic obstructive pulmonary disease: a Spanish multicenter study. Am J Respir Crit Care Med. 1996;154(5):1456-61. 
19. Mortensen EM, Coley CM, Singer DE, Marrie TJ, Obrosky DS, Kapoor WN, et al. Causes of death for patients with community-acquired Pneumonia: results from the Pneumonia Patient Outcomes Research Team cohort study. Arch Intern Med. 2002;162(9):1059-64.

20. Hasibi M, Rasoulinejad M, Hosseini SM, Davari P, Sahebian A Khashayar P. Epidemiological, clinical, laboratory findings and outcomes of disseminated tuberculosis in Tehran, Iran. South Med J. 2008;101(9):910-3

21. Horatio BF, Monteagudo-Chu MO. community-Acquired pneumonia in the Elderly. Am J Geriatr Pharmacother. 2010;8(1):48-57.
22. Jafari S, Soltanpour F, Soudbakhsh A, Safavi E, Navipour R, Hajizadeh E. Community-Acquired Pneumonia: a Comparison between elderly and nonelderly patients. Tehran Univers Med J. 2006;64(8):74-80.

23. Berger A, Edelsberg J, Oster G, Huang X, Weber DJ. Patterns of initial antibiotic therapy for community-acquired Pneumonia in US hospitals, 2000 to 2009. Am J Med Sci. 2014;347(5):347-56.

24. Kaplan V, Angus DC, Griffin MF, Clermont G, Scott Watson R, LindeZwirble WT. Hospitalized community-acquired pneumonia in the elderly: age-and sex-related patterns of care and outcome in the United States. Am J Respir Crit Care Med. 2002;165(6):766-72. 